\title{
Pharmacogenetically Guided Escitalopram Treatment for Pediatric Anxiety Disorders: Protocol for a Double-Blind Randomized Trial
}

\author{
Jeffrey R. Strawn ${ }^{1,2,3}{ }^{10}$, Ethan A. Poweleit ${ }^{2,3,4,5}$, Jeffrey A. Mills ${ }^{6}$, Heidi K. Schroeder ${ }^{1}$, Zoe A. Neptune ${ }^{1}$, \\ Ashley M. Specht ${ }^{1}$, Jenni E. Farrow ${ }^{1}$, Xue Zhang ${ }^{7}$, Lisa J. Martin ${ }^{7}{ }^{10}$ and Laura B. Ramsey ${ }^{2,8, *(D)}$
}

1 Anxiety Disorders Research Program, Department of Psychiatry \& Behavioral Neuroscience, College of Medicine, University of Cincinnati, Cincinnati, OH 45219, USA; strawnjr@uc.edu (J.R.S.); heysehk@uc.edu (H.K.S.); neptunza@uc.edu (Z.A.N.); huckabam@uc.edu (A.M.S.); farrowje@uc.edu (J.E.F.)

2 Cincinnati Children's Hospital Medical Center, Department of Pediatrics, Division of Clinical Pharmacology, Cincinnati, OH 45219, USA; poweleen@mail.uc.edu

3 Cincinnati Children's Hospital Medical Center, Department of Pediatrics, Division of Child \& Adolescent Psychiatry, Cincinnati, OH 45219, USA

4 Cincinnati Children's Hospital Medical Center, Department of Pediatrics, Division of Biomedical Informatics, College of Medicine, University of Cincinnati, Cincinnati, OH 45219, USA

5 Department of Biomedical Informatics, College of Medicine, University of Cincinnati, Cincinnati, OH 45219, USA

6 Department of Economics, Lindner College of Business, University of Cincinnati, Cincinnati, OH 45219, USA; millsjf@uc.edu

check for

updates

Citation: Strawn, J.R.; Poweleit, E.A.; Mills, J.A.; Schroeder, H.K.; Neptune, Z.A.; Specht, A.M.; Farrow, J.E.; Zhang, X.; Martin, L.J.; Ramsey, L.B. Pharmacogenetically Guided Escitalopram Treatment for Pediatric Anxiety Disorders: Protocol for a Double-Blind Randomized Trial. J. Pers. Med. 2021, 11, 1188. https:// doi.org/10.3390/jpm11111188

Academic Editor: Moon-Soo Lee

Received: 15 September 2021

Accepted: 2 November 2021

Published: 12 November 2021

Publisher's Note: MDPI stays neutral with regard to jurisdictional claims in published maps and institutional affiliations.

Copyright: () 2021 by the authors. Licensee MDPI, Basel, Switzerland. This article is an open access article distributed under the terms and conditions of the Creative Commons Attribution (CC BY) license (https:// creativecommons.org/licenses/by/ $4.0 /)$.
7 Cincinnati Children's Hospital Medical Center, Division of Human Genetics, College of Medicine, University of Cincinnati, Cincinnati, OH 45219, USA; xue.zhang@cchmc.org (X.Z.); lisa.martin@cchmc.org (L.J.M.)

8 Cincinnati Children's Hospital Medical Center, Division of Research in Patient Services, College of Medicine, University of Cincinnati, Cincinnati, $\mathrm{OH} 45219$, USA

* Correspondence: laura.ramsey@cchmc.org; Tel.: +1-513-803-8963

\begin{abstract}
Current pharmacologic treatments for pediatric anxiety disorders (e.g., selective serotonin reuptake inhibitors (SSRIs)) frequently use "one size fits all" dosing strategies based on average responses in clinical trials. However, for some SSRIs, including escitalopram, variation in CYP2C19 activity produces substantial variation in medication exposure (i.e., blood medication concentrations). This raises an important question: would refining current SSRI dosing strategies based on CYP2C19 phenotypes increase response and reduce side effect burden? To answer this question, we designed a randomized, double-blind trial of adolescents 12-17 years of age with generalized, separation, and/or social anxiety disorders $(\mathrm{N}=132)$. Patients are randomized $(1: 1)$ to standard escitalopram dosing or dosing based on validated CYP2C19 phenotypes for escitalopram metabolism. Using this approach, we will determine whether pharmacogenetically-guided treatment—compared to standard dosing - produces faster and greater reduction in anxiety symptoms (i.e., response) and improves tolerability (e.g., decreased risk of treatment-related activation and weight gain). Secondarily, we will examine pharmacodynamic variants associated with treatment outcomes, thus enhancing clinicians' ability to predict response and tolerability. Ultimately, developing a strategy to optimize dosing for individual patients could accelerate response while decreasing side effects-an immediate benefit to patients and their families. ClinicalTrials.gov Identifier: NCT04623099.
\end{abstract}

Keywords: selective serotonin reuptake inhibitor (SSRI); anxiety disorders; generalized anxiety disorder (GAD); pharmacogenetic; CYP2C19; pharmacokinetic; tolerability; side effects

\section{Introduction}

Anxiety disorders are the most common mental health conditions in youth, affecting up to $15 \%$ of children and adolescents [1-3] and, when untreated, result in persistent disability [4,5]. Early treatment of pediatric anxiety disorders has the potential to offset the 
substantial negative effects on the health and wellbeing of children and families. Currently, both cognitive behavioral therapy and antidepressant medications (e.g., selective serotonin reuptake inhibitors (SSRIs) and selective serotonin norepinephrine reuptake inhibitors (SNRIs)) present the most evidence for treating anxiety disorders in youth [6-8].

While all antidepressants decrease anxiety in youth, compared to SNRIs, SSRIs produce larger and earlier improvement in anxiety symptoms [9]. This is consistent with treatment recommendations that SSRIs are the first-line psychopharmacologic interventions in pediatric anxiety disorders. However, in prospective, randomized trials of SSRIs [10] as well as in our retrospective study of the SSRI escitalopram in pediatric anxiety disorders [11], only $50-60 \%$ of patients respond to these medications. Considering the relationship between SSRI exposure and response in pediatric anxiety and depressive disorders [12], pharmacogenetic variants in drug metabolizing enzymes-that determine exposure (i.e., plasma concentrations) - may help to predict treatment response.

Escitalopram is metabolized by several enzymes in the cytochrome P450 (CYP) system, with CYP2C19 and CYP3A4 contributing the most to the formation of inactive metabolites $[13,14]$. In patients with reduced CYP2C19 metabolism, escitalopram plasma concentrations are higher than in patients with normal CYP2C19 metabolism, putting these patients at higher risk of SSRI-related side effects. Additionally, there are patients with faster than normal metabolism and lower plasma escitalopram concentrations who are at high risk of treatment failure [15]. In adults, the influence of CYP2C19 metabolizer status on escitalopram pharmacokinetics (PK) is well-described [16,17]; however, there is less evidence on whether these variants are associated with treatment efficacy, especially in youth $[18,19]$. Moreover, in our prospective study of escitalopram in adolescents with anxiety, intermediate metabolizers improved by $10 \%$ more than normal metabolizers given the same dosing regimen [20].

Due to the frequency of SSRI-related side effects [21], clinicians often initiate SSRIs at low doses and slowly titrate these medications until either encountering a side effect or a response. If intolerable side effects occur, the SSRI dose is decreased, or the medication is discontinued. Slow titration minimizes side effects but risks under-treatment in many patients at the start of treatment and the lack of perceived treatment response may ultimately lead to a medication change, further delaying response [22]. Side effects are associated with SSRI concentrations (including escitalopram) in children and adolescents [12,23], as well as adults [24-27].

In pediatric patients, SSRI-related side effects include weight gain and activation [23,28-30]. The latter represents a hyperarousal event that is characterized by hyperactivity, impulsivity, disinhibition, restlessness, and/or insomnia [23,29]. Activation, which is markedly more common in pediatric patients than in studies of adults [29], impairs psychosocial functioning and decreases the likelihood of medication response [31]. SSRI-related activation emerges early in treatment (typically within the first 4-6 weeks) $[23,29]$ or following a dose increase [23], and symptoms may attenuate with dose reduction and/or resolve with discontinuation of the SSRI [29,32]. This temporal pattern is consistent with one prospective study in which higher plasma concentrations of the SSRI, fluvoxamine, were associated with activation [23]. Additionally, Sakolsky et al. found that higher venlafaxine plasma concentrations were associated with specific side effects in adolescents [12]. In our study of prospectively treated adolescents with GAD $(n=18)$ patients who experienced activation had higher escitalopram $\mathrm{C}_{\mathrm{MAX}}$ and $\mathrm{AUC}_{0-24}$ [20]. However, monitoring plasma SSRI concentrations is rarely seen in clinical practice. Thus, identifying factors that increase plasma concentrations (e.g., pharmacogenetic factors) could decrease the risk of these side effects. In adolescents, es/citalopram is significantly associated with increased BMI and greater weight gain compared to other SSRIs [33]. However, escitalopram-related weight gain varies [34] and may be obscured by symptoms of the underlying disorder (e.g., decreased appetite) or the short duration of most pediatric trials $[35,36]$. For example, in a patient with decreased appetite and weight loss (associated with core symptoms of major 
depressive disorder), weight gain could be confounded or obscured by improvement in neurovegetative symptoms.

The extant data supporting genotype-outcome associations are generated in adults $[37,38]$ because psychiatric pharmacogenetic studies rarely include pediatric patients. Multiple studies in adults have analyzed the association between pharmacokinetic (e.g., genes affecting plasma concentrations, CYP2D6 and CYP2C19) and pharmacodynamic genes with outcomes (e.g., genes affecting the serotonin pathway, SLC6A4 and HTR2A). The most commonly investigated pharmacodynamic gene is $S L C 6 A 4$, encoding a serotonin transporter that is the target of SSRIs; furthermore, the expression level of the SLC6A4 gene influences response to SSRIs [39-41].

When the expression of the drug target is low, less SSRI is necessary to produce a response, and when the expression is high, a higher SSRI concentration is necessary to inhibit the target and to produce the desired effect (Figure 1). A 44-base pair insertion in the promoter of SLC6A4 influences its expression, where the longer allele (with the insertion) is associated with higher expression, better response, and fewer side effects [42]. Additionally, there is a single nucleotide polymorphism (SNP), rs25531, that influences the expression of the longer allele [43]. Together, there are three alleles for SLC6A4 termed $\mathrm{L}_{\mathrm{A}}$, $\mathrm{L}_{\mathrm{G}}$, and $\mathrm{S}$. Variants in the HTR2A gene, encoding the serotonin receptor $2 \mathrm{~A}\left(5-\mathrm{HT}_{2 \mathrm{~A}}\right)$, have inconsistently been associated with es/citalopram response [39,44-47].

PHARMACOKINETIC FACTORS

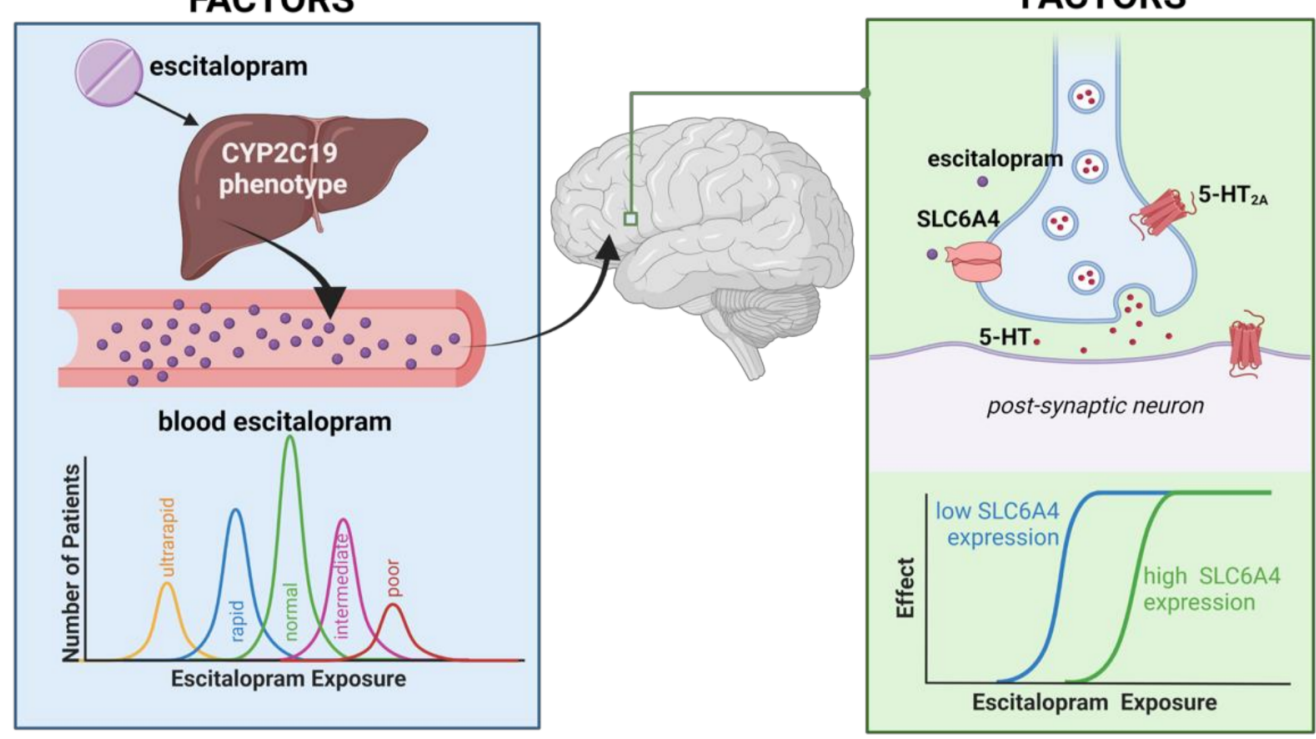

Figure 1. Multiple factors influence the efficacy and side effect profile of escitalopram in anxious adolescents. 5-HT, serotonin; SLC6A4, serotonin transporter. The current study primarily focuses on pharmacokinetic factors that impact response and tolerability (blue box), although, secondarily, pharmacodynamic influences (green box) are examined. Image created using Biorender.com.

The critical question facing clinicians is: would refining current antidepressant dosing strategies increase treatment response and reduce side effect burden? We propose that a substantial barrier to treating anxiety disorders with SSRIs is that current treatment approaches employ a "one size fits all" dosing strategy based on average responses in clinical trials. However, the identification of pharmacogenetic phenotypes related to response and side effect risks (as well as increased or decreased escitalopram exposure) allows clinicians to assess tolerability and optimize dosing for the individual patient. Ultimately, such a strategy may accelerate response while decreasing side effects - an immediate benefit to patients and their families. Using a randomized, double-blind clinical trial with dosing based on validated phenotypes for escitalopram metabolism, our study facilitates personalized 
dosing compared. This contrasts with current approach: "standard" initial escitalopram dose followed by dose titration until either encountering a response or treatment-limiting side effects. Using this approach, we may also identify pharmacodynamic variants associated with treatment outcomes, thus enhancing our ability to predict response and tolerability. Building pharmacokinetic models in pediatric patients that consider CYP2C19 metabolizer status will facilitate optimal dosing regimens and could be used to predict individual exposure in the future. Finally, this study has the potential to provide a critical foundation of knowledge that will benefit clinical practice and enhance antidepressant treatment response, safety, and tolerability in youth with other disorders (e.g., major depressive disorder).

To assess the impact of pharmacogenetically-guided dosing on adolescents with anxiety disorders, we designed a randomized, controlled trial that compares pharmacogeneticallyguided escitalopram dosing to standard dosing with regard to efficacy, tolerability, and safety and explore pharmacodynamic associations with responses. This approach is unique in that there have been no similarly designed trials in adults that address outcomes associated with CYP2C19-guided dosing of escitalopram. While adults and adolescents with anxiety share clinical features and treatment strategies, the lifetime burden in years of poor treatment outcomes is substantially greater in the adolescent population. The demonstration of clinical utility of pharmacogenetically-guided dosing is necessary for widespread adoption and insurance coverage of pharmacogenetic testing [48]. This trial has the potential to provide evidence needed for widespread adoption of pharmacogenetic testing in pediatric patients, increasing the likelihood that adolescents will respond to escitalopram (one of the most commonly prescribed SSRIs in youth) $[49,50]$.

\section{Study Protocol}

\subsection{Setting and Study Population}

The study was conducted at a single, outpatient site and recruited adolescents (age 1217 years, inclusive) with generalized, separation, and/or social anxiety disorder (pediatric anxiety triad) [51]. Exclusion criteria included patients with $>1$ prior SSRI trials of adequate dose and duration; a clinically significant, prolonged QTc; co-occurring DSM-5 mood, eating, bipolar, or psychotic disorder; intellectual disability; history of alcohol or substance use disorder within six months of screening (nicotine use is permitted); female patients of childbearing potential who were sexually active and not practicing a reliable method of contraception; patients who were pregnant, breast feeding, or lactating; or patients who were unable to attend the study visits.

The patients included in the trial met $D S M-5$ criteria for generalized, separation, and/or social anxiety disorder diagnosed by the MINI-KID [52] with no lifetime history of mania, obsessive compulsive disorder (OCD), or significant history of trauma. Additionally, the patients had a baseline Pediatric Anxiety Rating Scale (PARS) score $\geq 15$ and had not begun psychotherapy within eight weeks of screening. Written, informed consent and assent were obtained from all patients and their legal guardian(s). A buccal swab of the patient's cheek was collected and sent to a CAP/CLIA-certified facility for genotyping for 7 CYP2C19 no-function alleles $\left({ }^{*} 2, * 3,{ }^{*} 4, * 5, * 6, * 7\right.$, and $\left.{ }^{*} 8\right)$ and the increased function allele $\left({ }^{*} 17\right)$, with a ${ }^{*} 1$ genotype inferred from the absence of the previous alleles. The genotype-to-phenotype translation was performed according to the Clinical Pharmacogenetics Implementation Consortium standard [53]. The first patient was enrolled on 8 March 2021, and enrollment is expected to be completed in June 2025.

\subsection{Randomization}

When considering the optimal randomization strategy, we balanced factors that may influence the outcomes while ensuring that the most important aspects were accounted for in the initial randomization. As metabolizer status affects the dose a patient receives, it is critical to account for metabolizer status during randomization. Prior studies have also demonstrated that response to treatment may differ by sex [54]. While we recognize the 
importance of age and race as other potential factors, the literature on these effects is more limited; thus, they were not considered in the randomization. Patients were randomized (1:1) to a standard or a pharmacogenetically-guided escitalopram treatment.

\subsection{Medication and Dosing}

We selected escitalopram, a Food and Drug Administration (FDA) approved SSRI in adolescents [36] because it is commonly prescribed [49] and it has been extensively studied in pediatric patients with anxiety disorders/major depressive disorder, and pediatric pharmacokinetic data are available [55].

The treatment was double-blind, and escitalopram tablets were over-encapsulated to maintain the blind. The pharmacogenetically-guided dosing was based on published pharmacokinetic models [56] that incorporate CYP2C19 activity as well as age in adolescents $[57,58]$. These pharmacokinetic models standardize escitalopram exposure across CYP2C19 phenotypes, with normal metabolizers receiving $20 \mathrm{mg} /$ day as the reference. Exposure, at steady state, varies by $\leq 8 \%$ between each phenotype and that of a normal metabolizer (Figure 2).
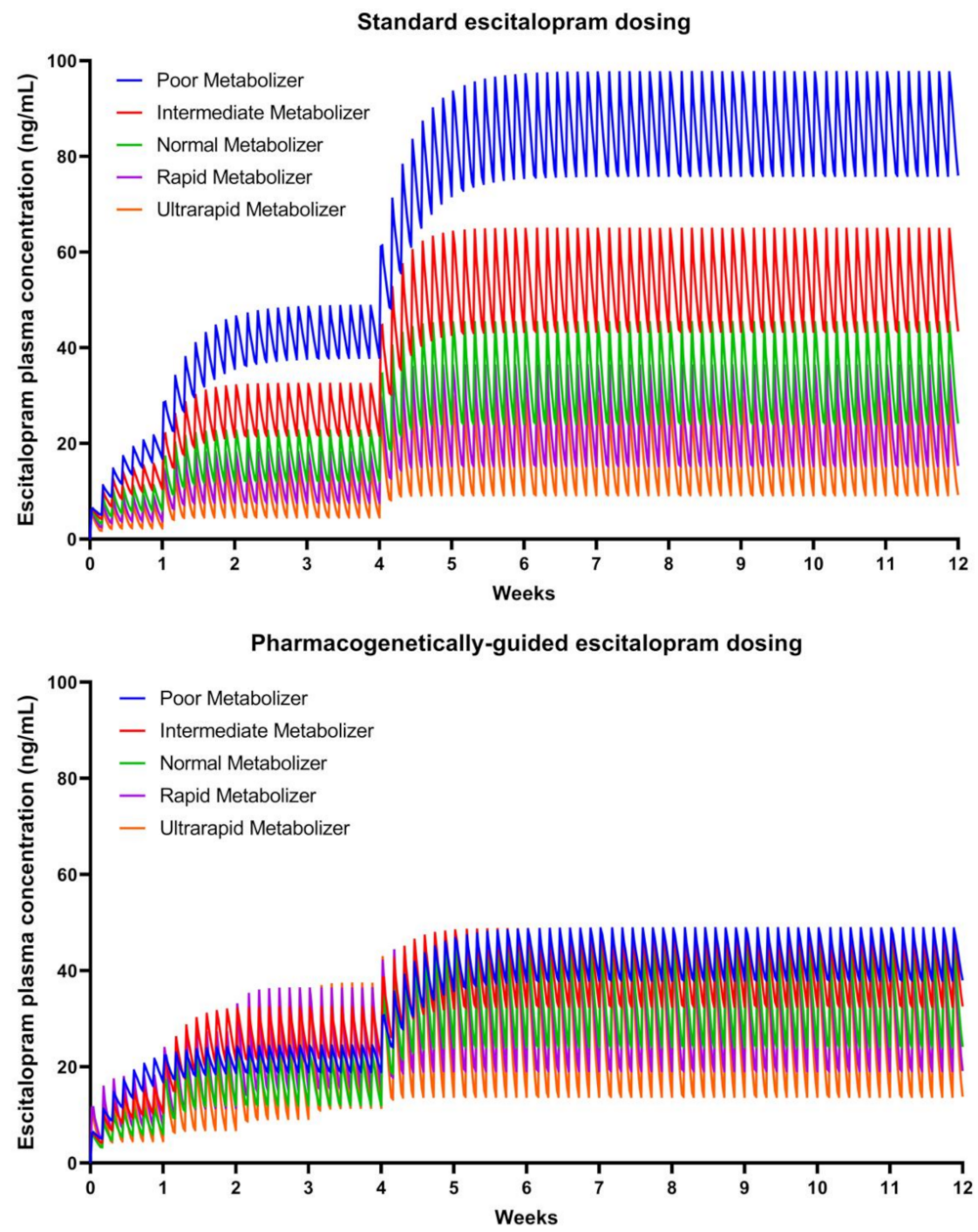

Figure 2. Standard (top) and pharmacogenetically-guided dosing (bottom) in adolescents result in considerable variation and harmonization of the concentration-time curves, respectively. Adapted from Strawn et al., 2017. 
In patients randomized to standard dosing, escitalopram was prescribed, consistent with the dosing strategy used in the adolescent registration trial that gave rise to the FDA approval for escitalopram in this age group [36]. In patients randomized to pharmacogenetically-guided escitalopram dosing, titration was based on the patient's CYP2C19 phenotype and predicted escitalopram exposure [56] (Figure 2).

\subsection{Primary Outcome}

Efficacy was assessed with both continuous (i.e., PARS) [59] and categorical measures of response (i.e., Clinical Global Impression-Improvement (CGI-I) and severity (CGI-S)) [60]. The CGI-I and CGI-S [60] were chosen because they have been used in most federally and industry-funded trials of pediatric anxiety disorders [10,61-64] and are reliably associated with decreases in anxiety and functional recovery in pediatric patients with the disorders being targeted in this study $[65,66]$. Thus, we chose an endpoint that is clear, informative, and relevant to clinical care and our hypothesis.

\subsection{Secondary Outcomes}

Activation was measured, at each visit, with the Treatment-Emergent Activation and Suicidality Assessment Profile (TEASAP) [67]. BMI was determined over a 12-week period and was used rather than the BMI percentile or the BMI z-score as we do not expect age-related changes in weight during the 12 weeks of the study. Vital signs, co-occurring depressive symptoms, and any worsening of anxiety were assessed at each visit.

Suicidality was monitored at every visit with the Columbia Suicide Severity Rating Scale (CSSRS) [68], consistent with prior trials of youth with anxiety and depressive disorders $[20,63,69]$. Additionally, while meta-analyses have consistently failed to identify an increased risk of suicidality in SSRI-treated adolescents with anxiety disorders [70,71], all SSRIs currently have FDA "boxed warning" related to "suicidal thinking and behavior." Recent data suggest that-when present-the possible risk of suicidality differs among antidepressant medications [71], with the highest rates being observed for paroxetine and venlafaxine. This was an additional factor that influenced our choice to use escitalopram.

We determined how HTR2A and SLC6A4 alleles that influence serotonin signaling predict response, when controlling for escitalopram exposure at a given dose. We expect that patients with alleles associated with low SLC6A4 and high HTR2A expression respond well with a lower exposure of escitalopram compared to patients with high SLC6A4 and low HTR2 $A$ expression, as we saw in our prospectively treated cohort [20]. We also expect that patients with low SLC6A4 expression and high HTR2A expression alleles experience more side effects (activation and more weight gain) than patients with high SLC6A4 expression and low HTR2A expression when exposure to escitalopram is high, based on off-target effects observed in paroxetine-treated adults [41].

\subsection{Hypotheses and Statistical Analyses}

The change in anxiety severity over the study was evaluated with mixed models. To evaluate differences between treatment arms, we included a time by study arm interaction in the model as well as a study arm.

We expect that anxiety decreases at a faster rate in those in the pharmacogeneticallyguided dosing arm compared to those randomized to standard dosing. Patients were included in the analyses regardless of whether they discontinued treatment, and missing data were accounted for with imputation modeling that accounts for dropout due to adverse events. Factors that may be incorporated in the mixed model include baseline characteristics (e.g., baseline anxiety severity and the type of primary anxiety disorder). Based on our randomized controlled trial of escitalopram for pediatric anxiety, we performed a power analysis using a mixed models procedure in PASS (100 simulations). This model allows us to account for the correlated nature of the longitudinal data. Based on our prior studies, we expected a 30.6\% decrease in PARS score (equivalent to 6 units on a 25 point scale with 26 SD units) in patients receiving standard dosing [23,63]. Assuming a 2-unit difference 
(additional 10\% reduction) in the overall mean PARS score (similar to the difference in IM and NMs receiving the same dose in [20]) between the two arms with 60 patients in each arm, we had $90 \%$ power at $\alpha=0.05$.

Activation was categorically analyzed, and the two arms were compared using logistic regression with factors differing by arm included as covariates. BMI changes over the 12week treatment period were analyzed using mixed models to evaluate longitudinal changes. To evaluate the power to detect differences in weight gain, we used anthropomorphic data from a clinical trial, which evaluated change in weight in adolescents (same age as the sample for this study) who were treated with SSRIs [72], including the subset treated with es/citalopram to estimate effect size. Using the observed 3.94 standard deviation units for weight change when on es/citalopram, we had $80 \%$ power to detect a difference as small as $2.03 \mathrm{~kg}$ at $\alpha=0.05$ using 60 patients in each arm of the study. Given that the mean weight gain in children treated with es/citalopram without pharmacogenetically-guided dosing was $4.66 \mathrm{~kg}$, this effect size is reasonable.

To evaluate the power to detect differences in discontinuation due to side effects, we considered both weight gain and activation. Prior studies have demonstrated a mean weight gain of $4.66 \mathrm{~kg}$ in children taking es / citalopram; thus, we expect approximately $50 \%$ of children in the standard arm to have a weight gain of $\geq 10 \mathrm{lbs}$ ( $4.53 \mathrm{~kg}$ ). Based on prior data, we expect $15 \%$ of children to experience activation while on es/citalopram. Assuming these two outcomes occur independently of each other, we expect $57.5 \%$ of patients who are randomized to standard dosing to have at least one of these outcomes. For the presence of either side effect, we have an $80 \%$ power to detect an odds ratio (OR) as small as 0.35 (equivalent to $32 \%$ in the pharmacogenetically-guided arm), with the side effect at $\alpha=0.05$ using 60 patients in each arm of the study. If we evaluate each side effect separately, we have an $80 \%$ power to detect an $\mathrm{OR}=0.34$ for weight gain and 0.07 for activation.

We will also examine whether pharmacogenetically-guided dosing-compared to standard dosing - produces differences in secondary outcomes (e.g., response/remission by CGI score, discontinuation, Figure 3). For secondary outcomes, we will use a Cox Proportional Hazards analysis to evaluate the time to the event.

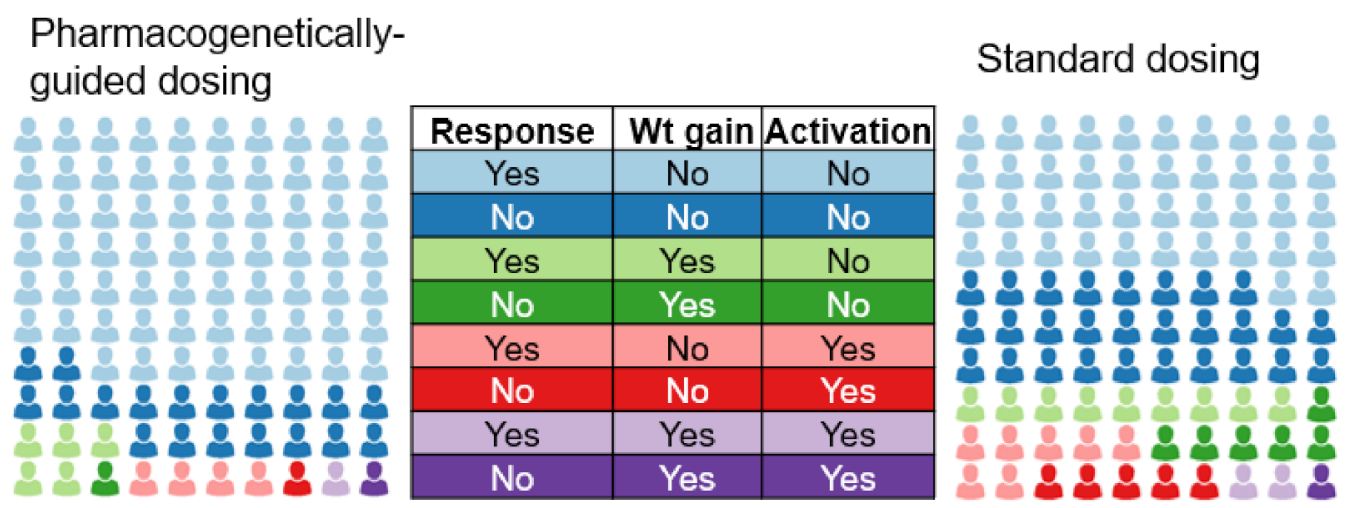

Figure 3. Expected response rates and rates of specific adverse events (weight gain and activation) in patients receiving pharmacogenetically-guided and standard escitalopram dosing.

\section{Impact of the Study}

This study is unique in that it assesses the impact of CYP2C19-guided dosing on treatment outcomes in patients with anxiety disorders. Additionally, it extends findings from adult studies associating CYP2C19 metabolizer status with escitalopram exposure and investigates whether pharmacodynamic variants influence response, all of which have yet to be evaluated in a large pediatric population treated with escitalopram. Predicting the right dose for each patient has many benefits, including reductions in inpatient admissions, decreased side effect burden (and associated improvement in adherence), decreased cost of care, and reductions in cumulative morbidity and mortality (e.g., 
suicide attempts/completion that result from untreated or inadequately treated symptoms). We designed this study to address the significant gap in the evidence base for pharmacogenetically-guided treatment of pediatric patients with anxiety disorders that may also be applicable to patients with major depressive disorder.

\section{Ethics Statement}

The study was conducted according to the guidelines of the Declaration of Helsinki and approved by the Institutional Review Board of the University of Cincinnati (protocol number: 2020-0957, approved 9 October 2020). Additionally, a data safety monitoring board oversees the conduct of the study. ClinicalTrials.gov Identifier: NCT04623099.

Author Contributions: Conceptualization, J.R.S., L.B.R. and L.J.M.; methodology, J.R.S., L.B.R., H.K.S., Z.A.N., A.M.S., X.Z. and L.J.M.; resources, J.R.S. and L.B.R.; writing-original draft preparation, J.R.S., L.B.R., X.Z., L.J.M. and E.A.P.; writing-review and editing, J.R.S., E.A.P., J.A.M., H.K.S., Z.A.N., A.M.S., X.Z., J.E.F., L.B.R., L.J.M.; visualization, L.B.R., J.R.S. and E.A.P.; supervision, L.B.R. and J.R.S.; project administration, L.B.R. and J.R.S. funding acquisition, L.B.R. and J.R.S. All authors have read and agreed to the published version of the manuscript.

Funding: This research was funded by the Eunice Kennedy Shriver National Institute of Child Health and Development (L.B.R. and J.R.S.), grant number R01HD099775.

Institutional Review Board Statement: The study was conducted according to the guidelines of the Declaration of Helsinki and approved by the Institutional Review Board of the University of Cincinnati (protocol number: 2020-0957, approved 9 October 2020).

Informed Consent Statement: Informed consent and assent is being obtained, respectively, from all parents/guardians and patients participating in the study.

Acknowledgments: The study team is grateful to Sara T. Varney, BA; Sarah Mossman, MAPCR; and Gayathri Kavikondala, MBA for assistance with the IND exemption request, protocol development, and study start-up. Select figures were created with biorender.com.

Conflicts of Interest: Strawn has received research support from NIH (National Institute of Mental Health/National Institute of Environmental Health Sciences/NICHD) and AbbVie. He has received material support from Myriad Genetics and royalties from the publication of two texts (Springer). He has served as an author for UpToDate and as an associate editor for Current Psychiatry and has received honoraria from American Academy of Pediatrics, American Academy of Child \& Adolescent Psychiatry, CMEology, and Neuroscience Education Institute. He has provided consultation to the Food and Drug Administration and Intracellular Therapeutics. Ramsey has received research support from NIH (NICHD). She has received an educational grant and provided consultation to BTG Specialty Pharmaceuticals. The remaining authors declare no conflict of interest. The funders had no role in the design of the study; in the collection, analyses, or interpretation of data; in the writing of the manuscript; or in the decision to publish the results. The NIH had no role in the design of the study; in planning of the analyses; in the writing of the manuscript; or in the decision to publish this work.

\section{References}

1. Baxter, A.J.; Vos, T.; Scott, K.M.; Ferrari, A.J.; Whiteford, H.A. The global burden of anxiety disorders in 2010. Psychol. Med. 2014, 44, 2363-2374. [CrossRef] [PubMed]

2. Kessler, R.C.; Berglund, P.; Demler, O.; Jin, R.; Walters, E.E. Lifetime prevalence and age-of-onset distributions' of DSM-IV disorders in the national comorbidity survey replication. Arch. Gen. Psychiatry 2005, 62, 593-602. [CrossRef] [PubMed]

3. Costello, E.J.; Angold, A.; Burns, B.J.; Stangl, D.K.; Tweed, D.L.; Erkanli, A.; Worthman, C.M. The Great Smoky Mountains Study of Youth. Goals, design, methods, and the prevalence of DSM-III-R disorders. Arch. Gen. Psychiatry 1996, 53, 1129-1136. [CrossRef] [PubMed]

4. Asselmann, E.; Wittchen, H.-U.; Lieb, R.; Höfler, M.; Beesdo-Baum, K. Associations of fearful spells and panic attacks with incident anxiety, depressive, and substance use disorders: A 10-year prospective-longitudinal community study of adolescents and young adults. J. Psychiatr. Res. 2014, 55, 8-14. [CrossRef]

5. Beesdo, K.; Bittner, A.; Pine, D.S.; Stein, M.B.; Höfler, M.; Lieb, R.; Wittchen, H.-U. Incidence of social anxiety disorder and the consistent risk for secondary depression in the first three decades of life. Arch. Gen. Psychiatry 2007, 64, 903-912. [CrossRef] 
6. Connolly, S.D.; Bernstein, G.A. Practice parameter for the assessment and treatment of children and adolescents with anxiety disorders. J. Am. Acad. Child Adolesc. Psychiatry 2007, 46, 267-283. [CrossRef]

7. Mohatt, J.; Bennett, S.M.; Walkup, J.T. Treatment of Separation, Generalized, and Social Anxiety Disorders in Youths. Am. J. Psychiatry 2014, 171, 741-748. [CrossRef]

8. Strawn, J.R.; Geracioti, L.; Rajdev, N.; Clemenza, K.; Levine, A. Pharmacotherapy for generalized anxiety disorder in adult and pediatric patients: An evidence-based treatment review. Expert Opin. Pharmacother. 2018, 19, 1057-1070. [CrossRef]

9. Strawn, J.R.; Mills, J.A.; Sauley, B.A.; Welge, J.A. The Impact of Antidepressant Dose and Class on Treatment Response in Pediatric Anxiety Disorders: A Meta-Analysis. J. Am. Acad. Child Adolesc. Psychiatry 2018, 57, 235-244. [CrossRef]

10. Walkup, J.T.; Albano, A.M.; Piacentini, J.; Birmaher, B.; Compton, S.N.; Sherrill, J.T.; Ginsburg, G.S.; Rynn, M.A.; McCracken, J.; Waslick, B.; et al. Cognitive behavioral therapy, sertraline, or a combination in childhood anxiety. N. Engl. J. Med. 2008, 359, 2753-2766. [CrossRef]

11. Aldrich, S.L.; Poweleit, E.A.; Prows, C.A.; Martin, L.J.; Strawn, J.R.; Ramsey, L.B. Influence of CYP2C19 Metabolizer Status on Escitalopram/Citalopram Tolerability and Response in Youth With Anxiety and Depressive Disorders. Front. Pharmacol. 2019, 10, 1-12. [CrossRef]

12. Sakolsky, D.J.; Perel, J.M.; Emslie, G.J.; Clarke, G.N.; Wagner, K.D.; Vitiello, B.; Keller, M.B.; Birmaher, B.; Asarnow, J.R.; Ryan, N.D.; et al. Antidepressant exposure as a predictor of clinical outcomes in the Treatment of Resistant Depression in Adolescents (TORDIA) study. J. Clin. Psychopharmacol. 2011, 31, 92-97. [CrossRef]

13. Olesen, O.V.; Linnet, K. Studies on the stereoselective metabolism of citalopram by human liver microsomes and cDNA-expressed cytochrome P450 enzymes. Pharmacology 1999, 59, 298-309. [CrossRef]

14. Lloret-Linares, C.; Bosilkovska, M.; Daali, Y.; Gex-Fabry, M.; Heron, K.; Bancila, V.; Michalopoulos, G.; Perroud, N.; RichardLepouriel, H.; Aubry, J.M.; et al. Phenotypic assessment of drug metabolic pathways and P-glycoprotein in patients treated with antidepressants in an ambulatory setting. J. Clin. Psychiatry 2018, 79. [CrossRef]

15. Hicks, J.K.; Bishop, J.R.; Sangkuhl, K.; Muller, D.J.; Ji, Y.; Leckband, S.G.; Leeder, J.S.; Graham, R.L.; Chiulli, D.L.; LLerena, A.; et al. Clinical Pharmacogenetics Implementation Consortium (CPIC) guideline for CYP2D6 and CYP2C19 genotypes and dosing of selective serotonin reuptake inhibitors. Clin. Pharmacol. Ther. 2015, 98, 127-134. [CrossRef]

16. Jukić, M.M.; Haslemo, T.; Molden, E.; Ingelman-Sundberg, M. Impact of CYP2C19 genotype on escitalopram exposure and therapeutic failure: A retrospective study based on 2,087 patients. Am. J. Psychiatry 2018, 175, 463-470. [CrossRef]

17. Steere, B.; Baker, J.A.R.; Hall, S.D.; Guo, Y. Prediction of in vivo clearance and associated variability of CYP2C19 substrates by genotypes in populations utilizing a pharmacogenetics-based mechanistic model. Drug Metab. Dispos. 2015, 43, 870-883. [CrossRef]

18. Ji, Y.; Schaid, D.J.; Desta, Z.; Kubo, M.; Batzler, A.J.; Snyder, K.; Mushiroda, T.; Kamatani, N.; Ogburn, E.; Hall-Flavin, D.; et al. Citalopram and escitalopram plasma drug and metabolite concentrations: Genome-wide associations. Br. J. Clin. Pharmacol. 2014, 78, 373-383. [CrossRef]

19. Uher, R.; Tansey, K.E.; Rietschel, M.; Henigsberg, N.; Maier, W.; Mors, O.; Hauser, J.; Placentino, A.; Souery, D.; Farmer, A.; et al. Common genetic variation and antidepressant efficacy in major depressive disorder: A meta-analysis of three genome-wide pharmacogenetic studies. Am. J. Psychiatry 2013, 170, 207-217. [CrossRef]

20. Strawn, J.R.; Mills, J.A.; Schroeder, H.; Mossman, S.A.; Varney, S.T.; Ramsey, L.B.; Poweleit, E.A.; Desta, Z.; Cecil, K.M.; Delbello, M.P. Escitalopram in adolescents with generalized anxiety disorder. J. Clin. Psychiatry 2020, 81, e1-e9. [CrossRef]

21. Cipriani, A.; Zhou, X.; Del Giovane, C.; Hetrick, S.E.; Qin, B.; Whittington, C.; Coghill, D.; Zhang, Y.; Hazell, P.; Leucht, S.; et al. Comparative efficacy and tolerability of antidepressants for major depressive disorder in children and adolescents: A network meta-analysis. Lancet 2016, 388, 881-890. [CrossRef]

22. Tulisiak, A.K.; Klein, J.A.; Harris, E.; Luft, M.J.; Schroeder, H.K.; Mossman, S.A.; Varney, S.T.; Keeshin, B.R.; Cotton, S.; Strawn, J.R. Antidepressant Prescribing by Pediatricians: A Mixed-Methods Analysis. Curr. Probl. Pediatr. Adolesc. Health Care 2017, 47, 15-24. [CrossRef]

23. Reinblatt, S.P.; Dosreis, S.; Walkup, J.T.; Riddle, M.A. Activation Adverse Events Induced by the Selective Serotonin Reuptake Inhibitor Fluvoxamine in Children and Adolescents. J. Child Adolesc. Psychopharmacol. 2009, 19, 119-126. [CrossRef]

24. Safer, D.J.; Zito, J.M. Treatment-Emergent Adverse Events from Selective Serotonin Reuptake Inhibitors by Age Group: Children versus Adolescents. J. Child Adolesc. Psychopharmacol. 2006, 16, 159-169. [CrossRef] [PubMed]

25. Safer, D.J. Raising the minimum effective dose of serotonin reuptake inhibitor antidepressants. J. Clin. Psychopharmacol. 2016, 36, 483-491. [CrossRef] [PubMed]

26. Hodgson, K.; Tansey, K.E.; Uher, R.; Dernovšek, M.Z.; Mors, O.; Hauser, J.; Souery, D.; Maier, W.; Henigsberg, N.; Rietschel, M.; et al. Exploring the role of drug-metabolising enzymes in antidepressant side effects. Psychopharmacology 2015, 232, $2609-2617$. [CrossRef] [PubMed]

27. Tibaldi, G.; Munizza, C.; Bollini, P.; Pampallona, S.; Kupelnick, B. Effectiveness of antidepressants. Meta-analysis of dose-effect relationships in randomised clinical trials. Br. J. Psychiatry 1999, 174, 297-303. [CrossRef]

28. Rynn, M.A.; Walkup, J.T.; Compton, S.N.; Sakolsky, D.J.; Sherrill, J.T.; Shen, S.; Kendall, P.C.; McCracken, J.; Albano, A.M.; Piacentini, J.; et al. Child/Adolescent anxiety multimodal study: Evaluating safety. J. Am. Acad. Child Adolesc. Psychiatry 2015, 54, 180-190. [CrossRef] 
29. Luft, M.J.; Lamy, M.; DelBello, M.P.; McNamara, R.K.; Strawn, J.R. Antidepressant-Induced Activation in Children and Adolescents: Risk, Recognition and Management. Curr. Probl. Pediatr. Adolesc. Health Care 2018, 48, 50-62. [CrossRef]

30. Zuckerman, M.L.; Vaughan, B.L.; Whitney, J.; Dodds, A.; Yakhkind, A.; MacMillan, C.; Raches, D.; Pravdova, I.; DeMaso, D.R.; Beardslee, W.R.; et al. Tolerability of selective serotonin reuptake inhibitors in thirty-nine children under age seven: A retrospective chart review. J. Child Adolesc. Psychopharmacol. 2007, 17, 165-174. [CrossRef]

31. Reid, A.M.; McNamara, J.P.H.; Murphy, T.K.; Guzick, A.G.; Storch, E.A.; Geffken, G.R.; Bussing, R. Side-effects of SSRIs disrupt multimodal treatment for pediatric OCD in a randomized-controlled trial. J. Psychiatr. Res. 2015, 71, 140-147. [CrossRef] [PubMed]

32. Wilens, T.E.; Biederman, J.; Kwon, A.; Chase, R.; Greenberg, L.; Mick, E.; Spencer, T.J.; Wilens, T.E.; Biederman, J.; Kwon, A.; et al. A systematic chart review of the nature of psychiatric adverse events in children and adolescents treated with selective serotonin reuptake inhibitors. J. Child Adolesc. Psychopharmacol. 2003, 13, 143-152. [CrossRef] [PubMed]

33. Calarge, C.A.; Mills, J.A.; Janz, K.F.; Burns, T.L.; Coryell, W.H.; Zemel, B.S. Body Composition in Adolescents During Treatment With Selective Serotonin Reuptake Inhibitors. Pediatrics 2017, 140, e20163943. [CrossRef] [PubMed]

34. Ramsey, L.B.; Aldrich, S.L.; Poweleit, E.; Prows, C.A.; Martin, L.J.; Strawn, J.R. Racial Differences in Escitalopram/CitalopramRelated Weight Gain in Children and Adolescents: A Natural Language Processing-Based Electronic Medical Record Study. J. Child Adolesc. Psychopharmacol. 2019, 29, 162-163. [CrossRef]

35. Isolan, L.; Pheula, G.; Salum, G.A., Jr.; Oswald, S.; Rohde, L.A.; Manfro, G.G. An open-label trial of escitalopram in children and adolescents with social anxiety disorder. J Child Adolesc Psychopharmacol 2007, 17, 751-760. [CrossRef]

36. Emslie, G.J.; Ventura, D.; Korotzer, A.; Tourkodimitris, S. Escitalopram in the treatment of adolescent depression: A randomized placebo-controlled multisite trial. J. Am. Acad. Child Adolesc. Psychiatry 2009, 48, 721-729. [CrossRef]

37. Green, D.J.; Mummaneni, P.; Kim, I.W.; Oh, J.M.; Pacanowski, M.; Burckart, G.J. Pharmacogenomics in the assessment of therapeutic risks versus benefits: Inside the United States Food and Drug Administration. Clin. Pharmacol. Ther. 2016, 99, 622-632. [CrossRef]

38. Maruf, A.A.; Greenslade, A.; Arnold, P.D.; Bousman, C. Antidepressant pharmacogenetics in children and young adults: A systematic review. J. Affect. Disord. 2019, 254, 98-108. [CrossRef]

39. Porcelli, S.; Fabbri, C.; Serretti, A. Meta-analysis of serotonin transporter gene promoter polymorphism (5-HTTLPR) association with antidepressant efficacy. Eur. Neuropsychopharmacol. 2012, 22, 239-258. [CrossRef]

40. Huezo-Diaz, P.; Uher, R.; Smith, R.; Rietschel, M.; Henigsberg, N.; Marušič, A.; Mors, O.; Maier, W.; Hauser, J.; Souery, D.; et al. Moderation of antidepressant response by the serotonin transporter gene. Br. J. Psychiatry 2009, 195, 30-38. [CrossRef]

41. Tomita, T.; Yasui-Furukori, N.; Nakagami, T.; Tsuchimine, S.; Ishioka, M.; Kaneda, A.; Sugawara, N.; Kaneko, S. The influence of 5-HTTLPR genotype on the association between the plasma concentration and therapeutic effect of paroxetine in patients with major depressive disorder. PLoS ONE 2014, 9, 1-6. [CrossRef]

42. Odgerel, Z.; Talati, A.; Hamilton, S.P.; Levinson, D.F.; Weissman, M.M. Genotyping serotonin transporter polymorphisms 5-HTTLPR and rs25531 in European- and African-American subjects from the National Institute of Mental Health's Collaborative Center for Genomic Studies. Transl. Psychiatry 2013, 3, e307-6. [CrossRef]

43. Hu, X.-Z.; Lipsky, R.H.; Zhu, G.; Akhtar, L.A.; Taubman, J.; Greenberg, B.D.; Xu, K.; Arnold, P.D.; Richter, M.A.; Kennedy, J.L.; et al. Serotonin Transporter Promoter Gain-of-Function Genotypes Are Linked to Obsessive-Compulsive Disorder. Am. J. Hum. Genet. 2006, 78, 815-826. [CrossRef]

44. Mrazek, D.A.; Rush, A.J.; Biernacka, J.M.; O’Kane, D.J.; Cunningham, J.M.; Wieben, E.D.; Schaid, D.J.; Drews, M.S.; Courson, V.L.; Snyder, K.A.; et al. SLC6A4 variation and citalopram response. Am. J. Med. Genet. Part B Neuropsychiatr. Genet. 2009, 150, 341-351. [CrossRef]

45. Biernacka, J.M.; Sangkuhl, K.; Jenkins, G.; Whaley, R.M.; Barman, P.; Batzler, A.; Altman, R.B.; Arolt, V.; Brockmöller, J.; Chen, C.H.; et al. The International SSRI Pharmacogenomics Consortium (ISPC): A genome-wide association study of antidepressant treatment response. Transl. Psychiatry 2015, 5, 1-9. [CrossRef]

46. Horstmann, S.; Lucae, S.; Menke, A.; Hennings, J.M.; Ising, M.; Roeske, D.; Müller-Myhsok, B.; Holsboer, F.; Binder, E.B. Polymorphisms in GRIK4, HTR2A, and FKBP5 show interactive effects in predicting remission to antidepressant treatment. Neuropsychopharmacology 2010, 35, 727-740. [CrossRef]

47. Niitsu, T.; Fabbri, C.; Bentini, F.; Serretti, A. Pharmacogenetics in major depression: A comprehensive meta-analysis. Prog. Neuro-Psychopharmacol. Biol. Psychiatry 2013, 45, 183-194. [CrossRef]

48. Keeling, N.J.; Rosenthal, M.M.; West-Strum, D.; Patel, A.S.; Haidar, C.E.; Hoffman, J.M. Preemptive pharmacogenetic testing: Exploring the knowledge and perspectives of US payers. Genet. Med. 2019, 21, 1224-1232. [CrossRef]

49. Czaja, A.S.; Valuck, R.J.; Anderson, H.D. Comparative safety of selective serotonin reuptake inhibitors among pediatric users with respect to adverse cardiac events. Pharmacoepidemiol. Drug Saf. 2013, 22, 607-614. [CrossRef]

50. Leeder, J.S.; Brown, J.T.; Soden, S.E. Individualizing the use of medications in children: Making goldilocks happy. Clin. Pharmacol. Ther. 2014, 96, 304-306. [CrossRef]

51. Compton, S.N.; Walkup, J.T.; Albano, A.M.; Piacentini, J.C.; Birmaher, B.; Sherrill, J.T.; Ginsburg, G.S.; Rynn, M.A.; McCracken, J.T.; Waslick, B.D.; et al. Child/Adolescent Anxiety Multimodal Study (CAMS): Rationale, design, and methods. Child Adolesc. Psychiatry Ment. Health 2010, 4, 1. [CrossRef] [PubMed] 
52. Sheehan, D.V.; Sheehan, K.H.; Shytle, R.D.; Janavs, J.; Bannon, Y.; Rogers, J.E.; Milo, K.M.; Stock, S.L.; Wilkinson, B. Reliability and validity of the Mini International Neuropsychiatric Interview for Children and Adolescents (MINI-KID). J. Clin. Psychiatry 2010, 71, 313-326. [CrossRef] [PubMed]

53. Caudle, K.E.; Dunnenberger, H.M.; Freimuth, R.R.; Peterson, J.F.; Burlison, J.D.; Whirl-Carrillo, M.; Scott, S.A.; Rehm, H.L.; Williams, M.S.; Klein, T.E.; et al. Standardizing terms for clinical pharmacogenetic test results: Consensus terms from the Clinical Pharmacogenetics Implementation Consortium (CPIC). Genet. Med. 2017, 19, 215-223. [CrossRef] [PubMed]

54. Strawn, J.R.; Lu, L.; Peris, T.S.; Levine, A.; Walkup, J.T. Research Review: Peadiatric Anxiety Disorders: What have we learnt in the last 10 years? J. Child Psychol. Psychiatry 2020. [CrossRef]

55. Periclou, A.; Rao, N.; Sherman, T.; Ventura, D.; Abramowitz, W. Single-dose pharmacokinetic study of escitalopram in adolescents and adults. In Proceedings of the Annual Meeting of the American College of Clinical Pharmacy, Atlanta, GA, USA, 2-5 November 2003.

56. Chang, M.; Tybring, G.; Dahl, M.L.; Lindh, J.D. Impact of Cytochrome P450 2C19 Polymorphisms on Citalopram/Escitalopram Exposure: A Systematic Review and Meta-Analysis. Clin. Pharmacokinet. 2014, 53, 801-811. [CrossRef]

57. Strawn, J.R.; Poweleit, E.A.; Ramsey, L.B. CYP2C19-Guided Escitalopram and Sertraline Dosing in Pediatric Patients: A Pharmacokinetic Modeling Study. J. Child Adolesc. Psychopharmacol. 2019, 29, 340-347. [CrossRef]

58. Strawn, J.R.; Poweleit, E.A.; Uppugunduri, C.R.S.; Ramsey, L.B. Pediatric Therapeutic Drug Monitoring for Selective Serotonin Reuptake Inhibitors. Front. Pharmacol. 2021, 12, 1-9. [CrossRef]

59. Riddle, M.A.; Ginsburg, G.S.; Walkup, J.T.; Labelarte, M.J.; Pine, D.S.; Davies, M.; Greenhill, L.; Sweeney, M.; Klein, R.; Abikoff, H.; et al. The Pediatric Anxiety Rating Scale (PARS): Development and psychometric properties. J. Am. Acad. Child Adolesc. Psychiatry 2002, 41, 1061-1069.

60. Guy, W. CGI Clinical Global Impressions. In ECDEU Assessment Manual; U.S. Department of Health, Education, and Welfare: Rockville, MD, USA, 1976; pp. 217-222.

61. Rynn, M.A.; Riddle, M.A.; Yeung, P.P.; Kunz, N.R. Efficacy and safety of extended-release venlafaxine in the treatment of generalized anxiety disorder in children and adolescents: Two placebo-controlled trials. Am. J. Psychiatry 2007, 164, 290-300. [CrossRef]

62. Fluvoxamine for the Treatment of Anxiety Disorders in Children and Adolescents. The Research Unit on Pediatric Psychopharmacology Anxiety Study Group. N. Engl. J. Med. 2001, 344, 1279-1285. [CrossRef]

63. Strawn, J.R.; Prakash, A.; Zhang, Q.; Pangallo, B.A.; Stroud, C.E.; Cai, N.; Findling, R.L. A randomized, placebo-controlled study of duloxetine for the treatment of children and adolescents with generalized anxiety disorder. J. Am. Acad. Child Adolesc. Psychiatry 2015, 54, 283-293. [CrossRef]

64. Strawn, J.R.; Compton, S.N.; Robertson, B.; Albano, A.M.; Hamdani, M.; Rynn, M.A. Extended Release Guanfacine in Pediatric Anxiety Disorders: A Pilot, Randomized, Placebo-Controlled Trial. J. Child Adolesc. Psychopharmacol. 2017, 27, 29-37. [CrossRef]

65. Caporino, N.E.; Sakolsky, D.; Brodman, D.M.; McGuire, J.F.; Piacentini, J.; Peris, T.S.; Ginsburg, G.S.; Walkup, J.T.; Iyengar, S.; Kendall, P.C.; et al. Establishing Clinical Cutoffs for Response and Remission on the Screen for Child Anxiety Related Emotional Disorders (SCARED). J. Am. Acad. Child Adolesc. Psychiatry 2017, 56, 696-702. [CrossRef]

66. Caporino, N.E.; Brodman, D.M.; Kendall, P.C.; Albano, A.M.; Sherrill, J.; Piacentini, J.; Sakolsky, D.; Birmaher, B.; Compton, S.N.; Ginsburg, G.; et al. Defining Treatment Response and Remission in Child Anxiety: Signal Detection Analysis Using the Pediatric Anxiety Rating Scale. J. Am. Acad. Child Adolesc. Psychiatry 2013, 52, 57-67. [CrossRef]

67. Bussing, R.; Murphy, T.K.; Storch, E.A.; McNamara, J.P.H.; Reid, A.M.; Garvan, C.W.; Goodman, W.K. Psychometric properties of the Treatment-Emergent Activation and Suicidality Assessment Profile (TEASAP) in youth with OCD. Psychiatry Res. 2013, 205, 253-261. [CrossRef]

68. Posner, K.; Brown, G.K.; Stanley, B.; Brent, D.A.; Yershova, K.V.; Oquendo, M.A.; Currier, G.W.; Melvin, G.A.; Greenhill, L.; Shen, S.; et al. The Columbia-Suicide Severity Rating Scale: Initial validity and internal consistency findings from three multisite studies with adolescents and adults. Am. J. Psychiatry 2011, 168, 1266-1277. [CrossRef]

69. Findling, R.L.; McCusker, E.; Strawn, J.R. A Randomized, Double-Blind, Placebo-Controlled Trial of Vilazodone in Children and Adolescents with Major Depressive Disorder with Twenty-Six-Week Open-Label Follow-Up. J. Child Adolesc. Psychopharmacol. 2020, 30, 355-365. [CrossRef]

70. Strawn, J.R.; Welge, J.A.; Wehry, A.M.; Keeshin, B.; Rynn, M.A. Efficacy and tolerability of antidepressants in pediatric anxiety disorders: A systematic review and meta-analysis. Depress. Anxiety 2015, 32, 149-157. [CrossRef]

71. Dobson, E.T.; Bloch, M.H.; Strawn, J.R. Efficacy and tolerability of pharmacotherapy in pediatric anxiety disorders: A network meta-analysis. J. Clin. Psychiatry 2019, 80, 17r12064. [CrossRef]

72. Mansoor, B.; Rengasamy, M.; Hilton, R.; Porta, G.; He, J.; Spirito, A.; Emslie, G.J.; Mayes, T.L.; Clarke, G.; Wagner, K.D.; et al. The Bidirectional Relationship Between Body Mass Index and Treatment Outcome in Adolescents with Treatment-Resistant Depression. J. Child Adolesc. Psychopharmacol. 2013, 23, 458-467. [CrossRef] 